\title{
Field investigation of near-surface metamorphism of snow
}

\author{
A.E. SLAUGHTER, ${ }^{1}$ E.E. ADAMS, ${ }^{1}$ P.J. STARON, ${ }^{1}$ R.H. SHERTZER, ${ }^{1}$ D.J. WALTERS, ${ }^{1}$ \\ D. $\mathrm{MCCABE}^{2}{ }^{2}$ D. CATHERINE, ${ }^{2}$ I. HENNINGER, ${ }^{2} \mathrm{~T}_{\text {. LEONARD, }}{ }^{2}$ M. COOPERSTEIN,${ }^{2}$ \\ H. MUNTER ${ }^{3}$ \\ ${ }^{1}$ Department of Civil Engineering, Montana State University, 205 Cobleigh Hall, Bozeman, Montana 59717-3900, USA \\ E-mail: andrew.e.slaughter@gmail.com \\ ${ }^{2}$ Yellowstone Club Ski Patrol, PO Box 161097, Big Sky, Montana 59716, USA \\ ${ }^{3}$ Chugach Powder Guides, PO Box 641, Girdwood, Alaska 99587, USA
}

\begin{abstract}
Buried surface hoar and near-surface faceted crystals are known to lead to deadly avalanches. Over the course of three winter seasons a field investigation detailing the environmental conditions leading to the formation of these crystals was performed. Weather stations on north- and south-facing aspects were established. The weather data were accompanied by detailed daily observations and grain-scale photographs of the snow surface. During the three seasons, 35 surface hoar and 47 near-surface facets events were recorded. The mean weather conditions for the entire dataset (all three seasons and both stations) were compared to the nights when surface hoar formed. The comparison yielded five parameters that were statistically linked to the formation of surface hoar: incoming longwave radiation, snow surface temperature, wind velocity, relative humidity and the air/snow temperature difference. A similar comparison between the daytime mean values for all days with near-surface facet events revealed three parameters with statistically significant differences. Thus, these parameters (short- and longwave radiation and relative humidity) could be statistically linked to facet formation. This research also suggests that environmental conditions in the daytime hours before and after surface hoar formation are statistically similar to the conditions causing nearsurface facet formation.
\end{abstract}

\section{INTRODUCTION}

Dry-slab avalanches cause extensive property damage and fatalities each year throughout the world. The majority of these avalanches slide on a weak layer that was formed at or near the snow surface and was subsequently buried (Birkeland, 1998; Schweizer and Lütschg, 2001). Near-surface facets (a layer that forms at or near the snow surface due to temperature gradients) accounted for $59 \%$ of avalanches in a case study in southwest Montana, USA (Birkeland, 1998). When buried by additional snowfall, surface hoar is particularly dangerous: $\sim 30 \%$ of skier-triggered avalanches have been associated with surface hoar (Birkeland, 1998; Schweizer and Lütschg, 2001). Understanding the conditions surrounding the formation of these crystals has been the topic of numerous research projects.

Surface hoar has been studied for decades (Seligman, 1936). Gow (1965) observed 'spike-like crystals' now referred to as surface hoar that formed during periods of still weather and clear skies. Lang and others (1984) proclaimed that their research was the first 'thorough quantitative study of surface hoar' and that formation was associated with significant temperature differences between the snow surface and air. Colbeck (1988) calculated the importance of temperature profiles and humidity to form surface hoar and concluded that 'some wind' is necessary for surface hoar growth, which was confirmed by Hachikubo and Akitaya (1997).

Although previous research exists (LaChapelle, 1970; LaChapelle and Armstrong, 1977; Armstrong, 1985; Akitaya and Shimizu, 1987), Colbeck (1989) conducted one of the first studies of near-surface facet by examining various scenarios that explain the existence of crystal growth just beneath the surface. In a case study by Fukuzawa and
Akitaya (1993) the snow surface metamorphosed into faceted grains over two nights of clear skies. Fierz (1998) reported that new low-density snow that accumulated on a denser pack and was followed by clear weather resulted in a crust on the surface with $1.5-2 \mathrm{~mm}$ facets underneath. The establishment of near-surface faceted crystals as an area of expanded study is partially credited to work conducted by Birkeland (1998) and Birkeland and others (1997, 1998), in which the term 'near-surface facets' was coined to describe 'snow formed by near-surface vapor pressure gradients resulting from temperature gradients near the snow surface.' Cooperstein and others (2004) reported that faceted crystals were better developed on south-facing slopes compared to a north-facing aspect at similar elevations. In the most complete quantitative investigation of near-surface faceting to date, Morstad and others (2007) successfully grew radiation-recrystallized near-surface facets in a laboratory. Similarly, Slaughter and others (2009) successfully simulated observed near-surface facet events from the field in the laboratory and demonstrated that despite the inherent difference between the laboratory and nature, facets grew under similar conditions in both scenarios.

These references are only a portion of the body of literature that examines the conditions surrounding surface hoar and near-surface facet formation (e.g. Slaughter, 2010; Stössel and others, 2010); however, only limited research exists that quantifies specific environmental conditions that surround their formation. To this end, weather stations were established in union with daily observations and crystalscale photographs of the snow surface. The following summarizes the results obtained from this field investigation, which is only a single constituent of an ongoing collaborative effort between researchers at Montana State 
University and the Yellowstone Club (YC) Ski Patrol. The specific goals of this paper are (1) to present the recorded field observations of surface hoar and near-surface facet formation (mainly due to radiation recrystallization) and (2) to propose statistical methods that serve as the first step to utilizing this data for further quantification of the conditions necessary to yield surface hoar and near-surface facet formation.

\section{METHODS}

Two study areas were selected, one on a north- and one on a south-facing slope located on Pioneer Mountain at the YC near Big Sky, Montana. The south $\left(2757 \mathrm{~m}\right.$; aspect $\left.187^{\circ}\right)$ and north (2532 m; aspect $0^{\circ}$ ) areas both have a slope angle of $\sim 30^{\circ}$ and have been used in previous research studies (Cooperstein and others, 2004; Staples and others, 2006; Adams and others, 2009; Slaughter and Adams, 2009; Slaughter and others, 2009; Slaughter, 2010). A detailed description of the weather stations is presented by Slaughter (2010).

The north and south sites are similarly instrumented to measure air temperature and humidity (Campbell Scientific, Inc. CS215 with 41303-5 naturally aspirated radiation $>$ shield), snow depth (NovaLynx Corp.), snow surface temperature (Everest Interscience, Inc. 4000.4ZL), incoming longwave radiation (Eppley Lab., Inc. PIR and Kipp \& Zonen CGR3), slope-parallel incoming and reflected shortwave radiation (LI-COR, Inc. Li200 and Kipp \& Zonen CMP3), wind speed and direction (Met One Instruments, Inc. 034B-L) and subsurface snow temperature taken at $2 \mathrm{~cm}$ intervals (Omega Eng., Inc. type T thermocouples). Slope-parallel radiation measurements were used to capture the amount of radiation impacting the snow surface including reflected radiation from the surroundings; a third station was located at the top of the American Spirit (Aspirit) lift. This station provided an unobstructed measure of incoming short- and longwave radiation (Eppley Lab., Inc. PSP and PIR). Data were recorded using Campbell Scientific, Inc. CR10(x) data loggers.

Daytime longwave radiation data from the 2007/08 season at the south location were unreliable due to solar contamination associated with the instruments used, the Eppley Lab, Inc. PIR (Albrecht and Cox, 1977). Generally, this problem is not a concern (Campbell Scientific, 2007). However, in certain applications of intense shortwave radiation (the situation at the south location) an additional correction is required that was not performed during the 2007/08 season. This problem was corrected in subsequent seasons by upgrading to Kipp \& Zonen CGR3 instruments that account for this problem.

A correction was defined for the 2007/08 season by comparing the mean daily values of longwave radiation, $L W$, at the south location with the mean daily values from the Aspirit location, $L W^{a}$. For the 2007/08 season the ratio of $L W$ to $L W^{a}$ was 1.57 , and for the combined data from the 2008/09 and 2009/10 seasons this ratio was 1.07. Assuming that the ratio of 1.07 applies to the 2007/08 season, a multiplier of $0.68(1.07 / 1.57)$ results, which was applied to the $L W$ values reported for the 2007/08 season.

Each season, the YC Ski Patrol maintained daily visual and written observations in addition to grain-scale images detailing the upper $5 \mathrm{~cm}$ of the snowpack. Snow crystal images were captured using a Panasonic PV-500, Olympus
SP-510 UZ or a Nikon Coolpix fitted with a $10 \times$ loupe from a Brunel $8 \times 30$ ocular. The same Brunel scope was utilized for the crystal classification. The daily records and images were cataloged with custom software designed for use in this project (Slaughter, 2010).

\section{RESULTS}

\subsection{Surface hoar}

During the 2007/08 (A), 2008/09 (B) and 2009/10 (C) winter seasons, 35 significant events of surface hoar were recorded. These events occurred at both the south and north weather stations, but not always at both. A significant event is defined by two criteria: (1) the field notes identify the crystals as surface hoar and (2) the images corroborate the field note statements. Table 1 gives the mean values of the measured weather data: longwave radiation, $L W$; air and snow temperature, $T_{\mathrm{a}}$ and $T_{\mathrm{s}}$; wind speed, $V_{\mathrm{w}}$; wind direction, Dir; relative humidity, $R H$, and incoming longwave radiation at Aspirit station, $L W^{a}$, for each event at the station(s) where crystals were observed. The means were computed using the data from the night prior to event date shown, from dusk to dawn (nightly). The mean was selected as the most intuitive single parameter for exploring the data, given that this paper presents only a first step in analyzing the data.

In addition to the above parameters, the interaction between the air and snow surface temperature was also computed, as $\Delta T=T_{\mathrm{a}}-T_{\mathrm{s}}$. This value is typically reported in the literature discussing surface hoar. The interactions between all of the parameters should be the topic of future research; such interactions were explored numerically by Slaughter (2010).

In some instances the incoming longwave radiation, $L W$, differs significantly between the north and south stations (e.g. A-1). The reason for the discrepancy is difficult to ascertain, the most likely being the influence of solar heating on the rock face above the south station that then radiates at night (Staples and others, 2006). Hence, the unobstructed Aspirit measurements of incoming longwave radiation are included in Table 1 to examine if this measurement may be an indicator of surface hoar formation.

In all but a few events, complete weather data and grainscale images of the crystals exist. Summarizing each of the 35 events is impractical, but to illustrate the information that may be ascertained, an example event from each season follows.

\subsubsection{Event A-6: 26 February 2008}

Large surface hoar formed at both the north $(4-8 \mathrm{~mm})$ and south (2-4 mm) locations the night between 25 and 26 February 2008. According to the field notes, the crystals developed on 2-3 mm 'broken stellars' at the north location and on $2 \mathrm{~mm}$ 'rimmed new snow' at the south. Figure 1 shows images of both the underlying crystals and the surface hoar crystals that developed at the north location. The surface hoar persisted at the north location through the following few days. No records of the surface hoar persisting at the south location were recorded.

\subsubsection{Events B-7 and B-8: 13 and 14 February 2009}

Surface hoar was reported at the north site on two consecutive days: 13 and 14 February 2009. According to 
Table 1. Summary of mean nightly weather conditions for the surface hoar events, including longwave radiation $\left(L W ; W \mathrm{~m}^{-2}\right)$, air $\left(T_{\mathrm{a}} ;{ }^{\circ} \mathrm{C}\right)$ and snow surface $\left(T_{\mathrm{s}} ;{ }^{\circ} \mathrm{C}\right)$ temperature, wind speed $\left(V_{\mathrm{w}} ; \mathrm{m} \mathrm{s}^{-1}\right)$ and direction $\left(\operatorname{Dir} ;{ }^{\circ}\right)$, relative humidity $(R H ; \%)$, and the difference between the air and snow temperatures $\left(\Delta T ;{ }^{\circ} \mathrm{C}\right)$. Blank regions indicate that no surface hoar was found at that location. Incoming longwave at Aspirit is denoted as $L W^{\text {a }}$ and - indicates missing data

Season A: 2007/08

Season B: 2008/09

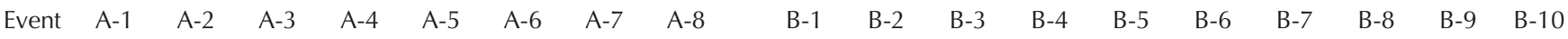
Date 24Jan 15 Feb 19 Feb 20 Feb 22 Feb 26 Feb 10 Mar 30 Mar 23 Jan 30 Jan 31 Jan 4 Feb 7 Feb 8 Feb 13 Feb 14 Feb 28 Feb 13 Mar

North

$\begin{array}{llll}\text { LW } & 252 & 225 & 217\end{array}$

$\begin{array}{llll}T_{\mathrm{a}} & -13.1 & -11.1 & -4.8\end{array}$

$\begin{array}{llll}206 & 274 & 206 & 199\end{array}$

$\begin{array}{llll}-8.2 & -8.8 & -7.6 & -15.9\end{array}$

$\begin{array}{llll}-18.0 & -15.0 & -17.6 & -22.4\end{array}$

$\begin{array}{lllll}1.4 & 1.1 & 1.2 & 1.3 & 0.5\end{array}$

$\begin{array}{llll}151 & 132 & 165 & 152\end{array}$

$\begin{array}{lllll}64 & 81 & 57 & 79 & 83\end{array}$

$\begin{array}{llll}\text { Dir } & 155 & 117 & 142\end{array}$

RH $\quad 71 \quad 78 \quad 54$

$\begin{array}{llll}\Delta T & 9.0 & 5.2 & 10.5\end{array}$

$\begin{array}{lllll}9.9 & 6.2 & 10.0 & 6.5 & 3.4\end{array}$

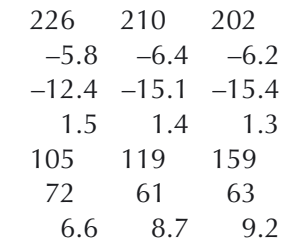

$\begin{array}{llllll}376 & 417 & 371 & 277 & 369 & 267\end{array}$

LW 354

$T_{\mathrm{a}} \quad-10.5$

$\begin{array}{ll}T_{\mathrm{s}} & -19.7 \\ V_{\mathrm{w}} & 1.3\end{array}$

$\begin{array}{ll}V_{\mathrm{w}} & 1.3\end{array}$

Dir 82

RH 40

$\Delta T \quad 9.2$

$\begin{array}{llllll}-4.7 & -0.9 & -6.6 & -9.8 & -7.5 & -15.9\end{array}$

$\begin{array}{llllll}-11.5 & -9.7 & -10.5 & -15.8 & -15.0 & -22.4\end{array}$

$\begin{array}{rrrrrr}1.4 & 1.6 & 1.1 & 0.9 & 1.4 & 1.1\end{array}$

$\begin{array}{rrrrrr}76 & 45 & 53 & 93 & 122 & 89 \\ 51 & 18 & 57 & 84 & 57 & 74\end{array}$

$\begin{array}{llllll}51 & 18 & 57 & 84 & 57 & 74\end{array}$

Aspirit

$\begin{array}{lllllllll}L W^{\text {a }} & 167 & 215 & 194 & 182 & 183 & 203 & 180 & 188\end{array}$

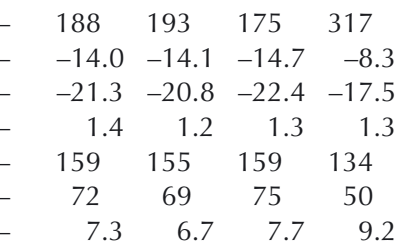

190

$-7.1$

$-14.9$

1.2

246

55

7.8

\begin{tabular}{|c|c|c|c|c|c|c|c|c|c|c|c|c|c|c|c|c|c|}
\hline \multirow{2}{*}{ Event } & \multicolumn{17}{|c|}{ Season C: 2009/10 } \\
\hline & $\mathrm{C}-1$ & $\mathrm{C}-2$ & $\mathrm{C}-3$ & C-4 & C-5 & C-6 & $\mathrm{C}-7$ & $C-8$ & C-9 & C-10 & $\mathrm{C}-11$ & C-12 & $C-13$ & C-14 & C-15 & C-16 & $\mathrm{C}-17$ \\
\hline Date & $26 \mathrm{Dec}$ & $27 \mathrm{Dec}$ & 7 Jan & 11 Jan & 12 Jan & 20 Jan & 28 Jan & 3 Feb & 7 Feb & 8 Feb & 16 Feb & 26 Feb & 1 Mar & 4 Mar & 7 Mar & 15 Mar & 24 Mar \\
\hline \multicolumn{18}{|l|}{ North } \\
\hline$L W$ & 196 & 189 & & & 223 & & 204 & 272 & 274 & & 282 & & 220 & & 226 & 214 & 199 \\
\hline$T_{\mathrm{a}}$ & -14.1 & -10.3 & & & -3.8 & & -9.5 & -9.4 & -8.6 & & -6.5 & & -4.6 & & -3.7 & -4.5 & -7.9 \\
\hline$T_{\mathrm{s}}$ & -21.0 & -19.3 & & & -12.5 & & -16.6 & -15.1 & -15.2 & & -13.1 & & -13.0 & & -12.3 & -13.5 & -17.0 \\
\hline$V_{w}$ & 1.0 & 1.3 & & & 1.1 & & 1.0 & 1.0 & 1.4 & & 1.1 & & 1.2 & & 1.2 & 1.5 & 1.5 \\
\hline Dir & 137 & 160 & & & 193 & & 161 & 157 & 158 & & 152 & & 133 & & 162 & 157 & 164 \\
\hline$R H$ & 78 & 65 & & & 66 & & 81 & 80 & 78 & & 78 & & 73 & & 67 & 73 & 67 \\
\hline$\Delta T$ & 6.9 & 9.0 & & & 8.7 & & 7.1 & 5.7 & 6.6 & & 6.6 & & 8.4 & & 8.6 & 9.0 & 9.1 \\
\hline \multicolumn{18}{|l|}{ South } \\
\hline$L W$ & 246 & 185 & 228 & 217 & & - & - & - & 209 & 183 & 270 & 218 & 213 & 210 & 222 & 209 & 271 \\
\hline$T_{\mathrm{a}}$ & -14.3 & -9.4 & -18.9 & -1.7 & & - & - & - & -9.9 & -11.7 & -7.6 & -9.1 & -6.4 & -6.3 & -4.1 & -4.3 & -8.2 \\
\hline$T_{\mathrm{s}}$ & -21.8 & -17.8 & -26.8 & -10.2 & & - & - & - & -14.6 & -17.1 & -13.5 & -15.0 & -12.7 & -10.9 & -9.1 & -9.5 & -13.9 \\
\hline$V_{w}$ & 0.8 & 1.7 & 1.2 & 1.3 & & - & - & - & 1.3 & 1.4 & 1.2 & 1.4 & 0.9 & 1.1 & 1.0 & 1.2 & 1.3 \\
\hline Dir & 100 & 60 & 77 & 108 & & - & - & - & 66 & 72 & 79 & 108 & 115 & 105 & 113 & 64 & 64 \\
\hline RH & 74 & 59 & 53 & 50 & & - & - & - & 82 & 75 & 82 & 79 & 78 & 82 & 69 & 71 & 70 \\
\hline$\Delta T$ & 7.6 & 8.3 & 7.8 & 8.5 & & - & - & - & 4.7 & 5.4 & 5.9 & 5.9 & 6.2 & 4.7 & 5.0 & 5.2 & 5.7 \\
\hline \multicolumn{18}{|l|}{ Aspirit } \\
\hline$L W^{\mathrm{a}}$ & 170 & - & 131 & 201 & 207 & 188 & 217 & 219 & 226 & 176 & 202 & 199 & 199 & 212 & 208 & 195 & 178 \\
\hline
\end{tabular}

field notes on 13 February, the surface hoar was '[half] surface hoar and [half] decomposing stellars' $1 \mathrm{~mm}$ in size. The following day, 14 February, the surface hoar was more pronounced and reported as $1.5 \mathrm{~mm}$ in size, but was decomposing at the time of the observations. Images from the north on both days are shown in Figure 2.

Interestingly, at the south location the formation of nearsurface facets due to radiation recrystallization was reported. At $1313 \mathrm{~h}$ on 13 February the field notes indicated near-surface facets in the top $2 \mathrm{~cm}$ of the snow, as shown in Figure 3. On the following day, 14 February, the field notes stated: 'Facets [are present] in the surface snow. Some look larger than yesterday, but not as many striations are noted. [The crystals do not] seem to be standard [radiationrecrystallization facets]. Perhaps there was some small amount of decomposition and regrowth overnight.'

Generally, the weather conditions at the north and south locations were similar; for example, Figure 4a compares the incoming longwave radiation. Snow surface temperature, as shown in Figure $4 b$, demonstrates one of the only obvious differences observed between the locations. During the daytime the south location warmed $\sim 15^{\circ} \mathrm{C}$ on 13 February, while the north had minimal temperature fluctuations. The formation of near-surface facets as well as the coincidental 

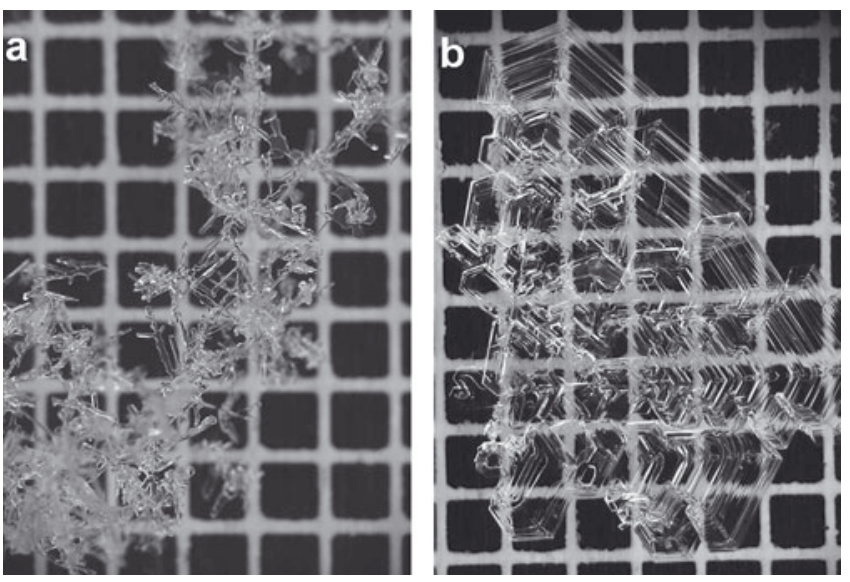

Fig. 1. Images ( $1 \mathrm{~mm}$ grid) from event A-5 showing (a) the underlying snow crystals and (b) the surface hoar crystals that developed on the surface.

formation of near-surface facets and surface hoar is discussed further in section 5 .

\subsubsection{Event C-5: 12 January 2010}

A significant and persistent surface hoar layer developed between 11 and 12 January 2010 at the north location. The field notes state 'two layers of surface hoar [were] stacked on top of each other.' At the surface, $4-8 \mathrm{~mm}$ crystals were observed and, just below the surface, $2-4 \mathrm{~mm}$ surface hoar crystals were present with decomposing new snow underneath both layers (see Fig. 5). The lower layer of surface hoar likely formed the night prior to the event. Surface hoar was observed at the south location on 11 January (C-4), but no observations at the north station were conducted. On 12 January the south station experienced significant melting and no surface hoar was present.

The persistence of this layer of surface hoar is notable. The field notes indicate its presence for 15 days: on 13 January $7 \mathrm{~cm}$ down, the $1 \mathrm{~cm}$ of surface hoar is still persistent'; on 21 January 'surface hoar is buried under $13 \mathrm{~cm}$ of snow'; and on 27 January 'surface hoar is still buried approximately $30 \mathrm{~cm}$ under [the] surface'. There is no further mention of this layer after 27 January.
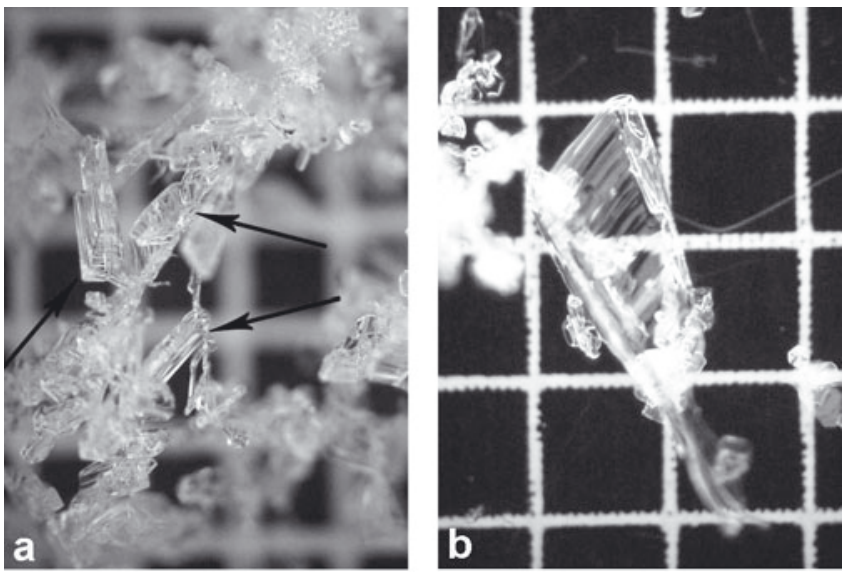

Fig. 2. Images from events B-7 and B-8 showing surface hoar that formed at the north location on (a) 13 February and (b) 14 February 2009 .
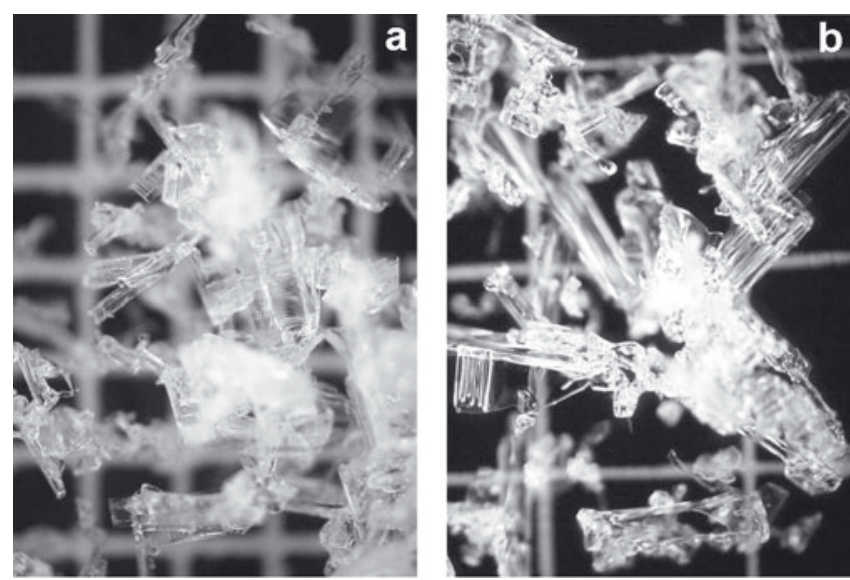

Fig. 3. Images showing the faceted crystals that formed at the south location on (a) 13 February (event B-7) and (b) 14 February (event B-8) 2009 .

\subsection{Near-surface facets}

During the three seasons of observations, near-surface facets were recorded on 47 days. These events occurred exclusively at the south weather station. An event was defined using the same criteria as for surface hoar (section 3.1). Table 2 includes the daytime mean values of the measured weather data. To distinguish between the surface hoar and near-surface facet events, the latter are denoted using double letters (e.g. AA-1 refers to the first near-surface facet event in the 2007/08 season). The means were computed using data from the event date shown, from dawn to dusk (daytime).

In addition to the individual parameters, the ratio between long- and shortwave radiation was considered. This value was indicated to be of critical importance by
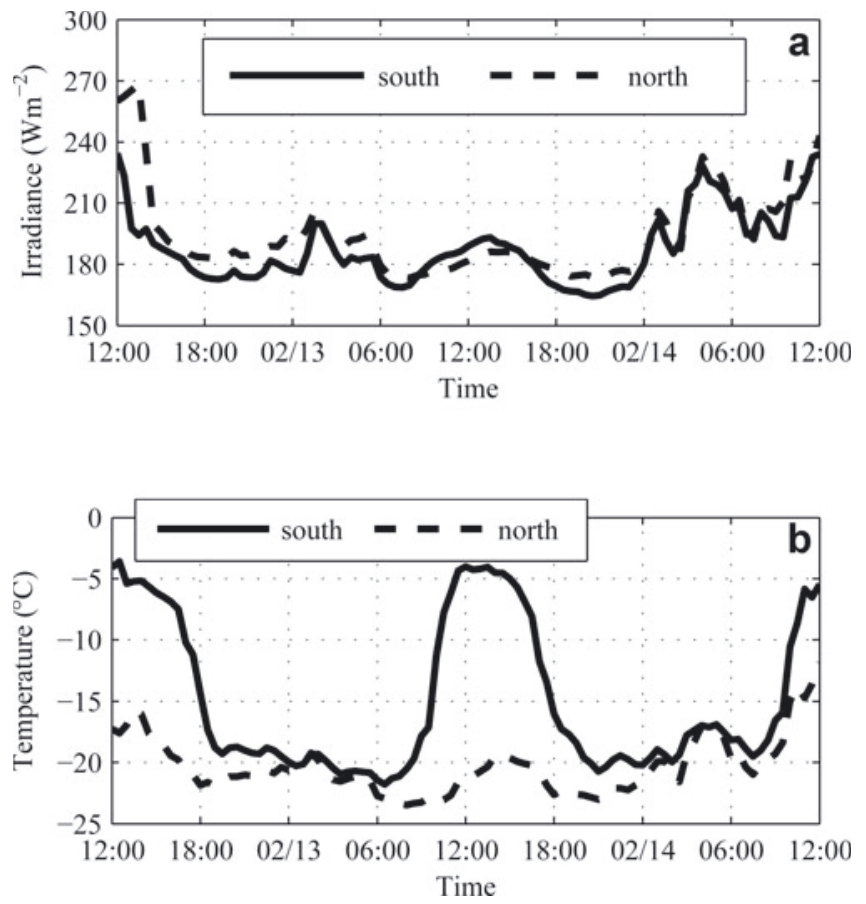

Fig. 4. Weather data from events B-7 and B-8 comparing the (a) incoming longwave radiation and (b) snow surface temperature between the north and south locations, 12-14 February 2009. 

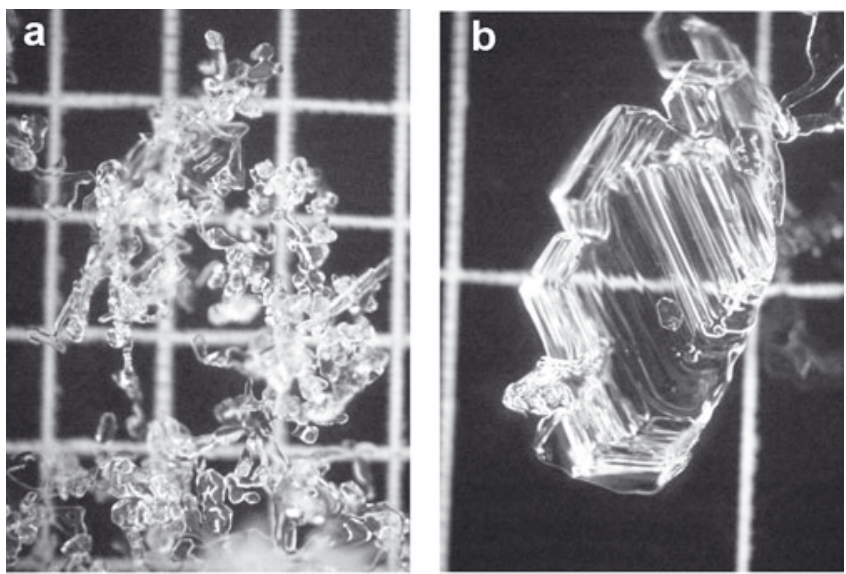

Fig. 5. Images from event C-5 showing the (a) underlying snow crystals and (b) surface hoar crystals that developed on the surface.

Slaughter (2010) and Slaughter and Adams (in press). As with the case of surface hoar, the interactions between all of the parameters should be the topic of future research. Additionally, the Aspirit data were included in the analysis to assess if the unobstructed radiation measurements were an indicator of near-surface facet formation.

\subsubsection{Event AA-2: 14 February 2008}

Event AA-2 was a widespread near-surface facet event and has been the subject of additional analysis (Slaughter and others, 2009). Initial observations that occurred at $1100 \mathrm{~h}$ at the south station reported minimal amounts of surface hoar, as shown in Figure 6a. A second observation at $1400 \mathrm{~h}$ indicated that additional 'needle-like' growth had occurred, as shown in Figure 6b.

The formation of these crystals occurred with air temperatures that rose between $0600 \mathrm{~h}$ and $1400 \mathrm{~h}$ from $-17^{\circ} \mathrm{C}$ to $-4^{\circ} \mathrm{C}$ and snow surface temperatures that increased from $-25^{\circ} \mathrm{C}$ to $-4^{\circ} \mathrm{C}$. The facets formed in new snow that had fallen the previous day; the density was reported as $20 \mathrm{~kg} \mathrm{~m}^{-3}$. This warming was more pronounced in the subsurface. It was reported that the snow between 1 and $5 \mathrm{~cm}$ deep was moist. Thus, the temperature gradient in the upper centimeter of snow was $\sim 400^{\circ} \mathrm{C} \mathrm{m}^{-1}$. The facets persisted, being buried on 16 February by $4-5 \mathrm{~cm}$ of new snow, as recorded in the field notes: 'facets are still visible on the upper crust interface.'

\subsubsection{Events BB-3 and BB-4: 12 and 13 February 2009}

On 12 February 2009, observations showed that new snow became faceted in a matter of hours. The initial observation at $1015 \mathrm{~h}$ reported $1-2 \mathrm{~mm}$ of new snow (Fig. 7a). At $1245 \mathrm{~h}$, facets measuring $1 \mathrm{~mm}$ were observed (Fig. $7 \mathrm{~b}$ ) at the snow surface with a moist layer between 2 and $5 \mathrm{~cm}$. Facets at the surface were observed for the following two days (Fig. 7c and d). As mentioned in section 3.1, this event occurred during the day after a surface hoar event at the north location. This relationship is discussed further in section 5 .

The field notes on 14 February state '[the facets] look larger than yesterday, but not as many striations are noted [and they] don't seem to be standard [radiation-recrystallized near-surface facets].' Hence, it is unknown if the facets observed on the days following the initial event formed during the day, night, both, or simply persisted. Thus, the
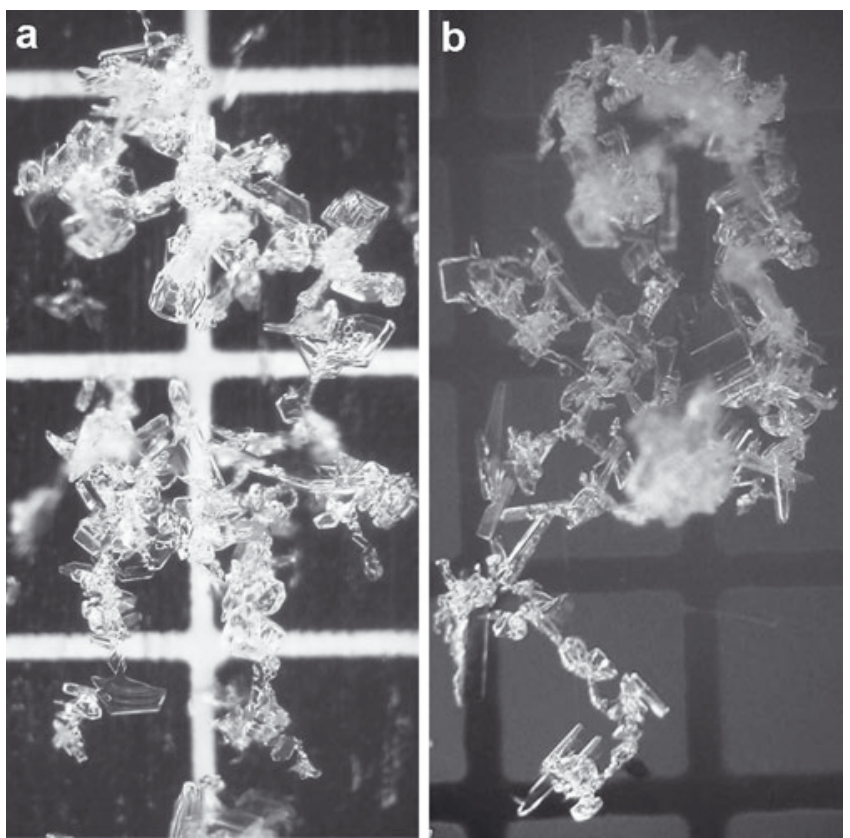

Fig. 6. Images of near-surface facet event AA-2 on 14 February 2008. (a) The initial observation at $1100 \mathrm{~h}$ and (b) a second observation at $1400 \mathrm{~h}$.

days following the 13 February event were not included as an event. However, these faceted crystals persisted, being buried by $9 \mathrm{~cm}$ of new snow the night of 14 February (Fig. 8).

\subsubsection{Event CC-12: 27 March 2010}

An interesting near-surface event occurred on 27 March 2010. On 26 March, $20 \mathrm{~cm}$ of new snow was recorded and a trace of new snow was recorded on the night between 26 and 27 March. At $1245 \mathrm{~h}$ on 27 March, near-surface
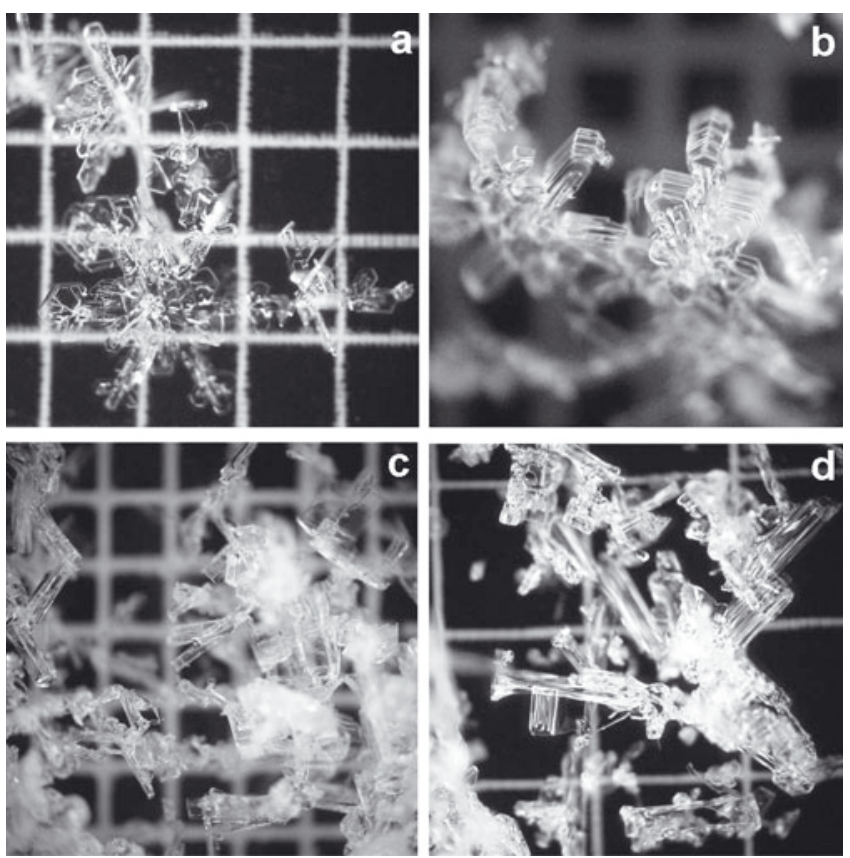

Fig. 7. Images of a near-surface facet event that $(a, b)$ occurred at the south location on 12 February 2009, (c) continued on 13 February and (d) was also observed on 14 February. 
Table 2. Summary of mean daytime weather conditions for days with near-surface facet events for each of the three seasons: slope-parallel shortwave $(S W)$ and longwave $(L W)$ radiation; air $\left(T_{\mathrm{a}}\right)$ and snow surface $\left(T_{\mathrm{s}}\right)$ temperature; wind speed, $V_{\mathrm{w}}$, and direction, Dir, and relative humidity, $R H$. Superscript 'a' denotes the Aspirit station, - indicates missing data and, as detailed in section 2, a correction was applied to the 2007/08 longwave data

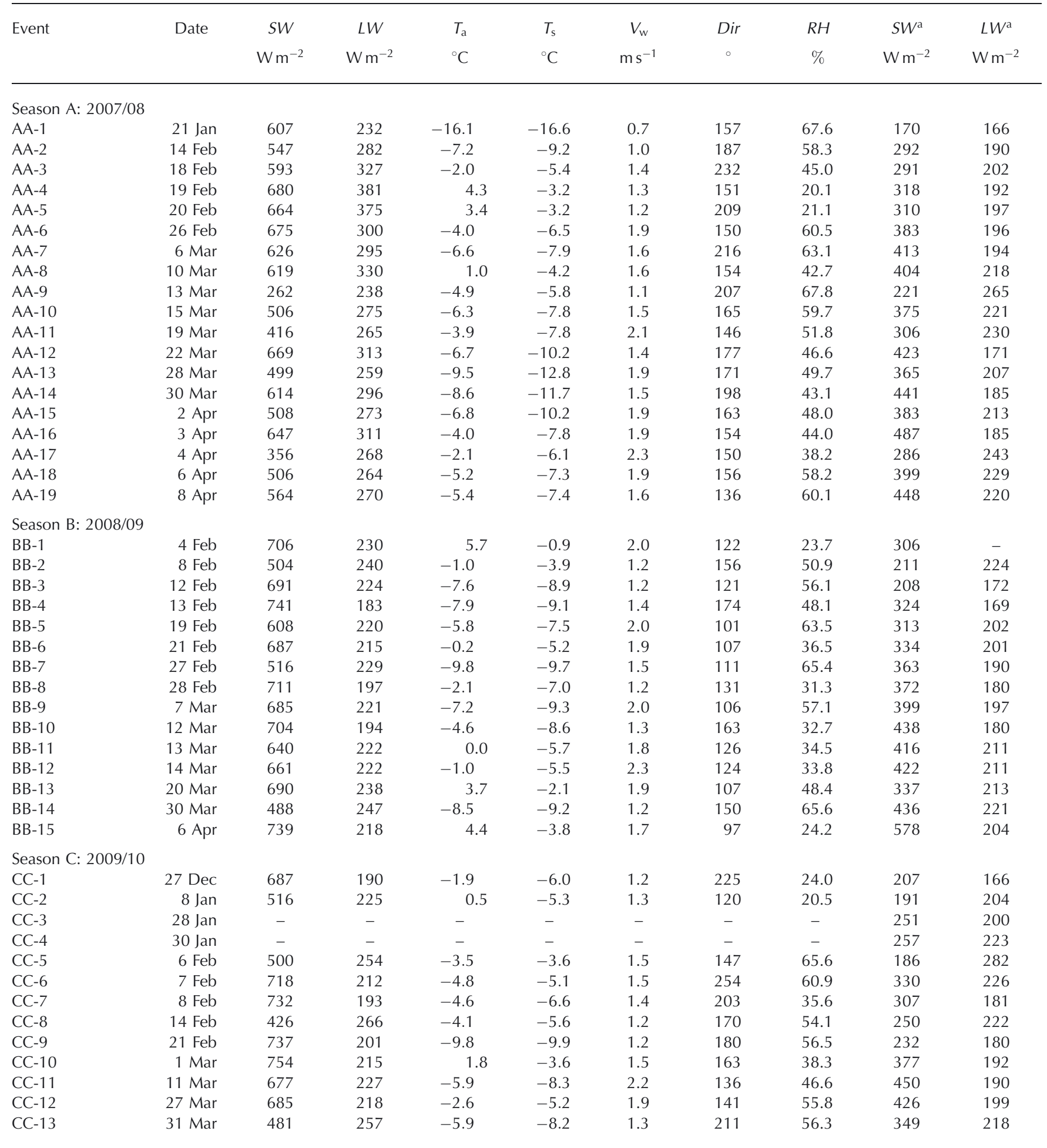

facets were observed that, as shown in Figure 9, grew as columns perpendicular to the plane of the new snow crystals. Crystals behaving in a similar fashion were observed in many of the events during all three winter seasons. Given the snow temperature on 27 March, this behavior is expected. It was near $-5^{\circ} \mathrm{C}$, precisely in the columnar, $c$-axis growth region on the snow crystal morphology diagram (Nakaya, 1954).

\section{ANALYSIS}

\subsection{Surface hoar}

The general weather conditions were compared to the eventspecific conditions to determine which environmental parameters may be statistically related to the formation of surface hoar. First, the data from both stations and all three seasons were combined into a single dataset. This was done 


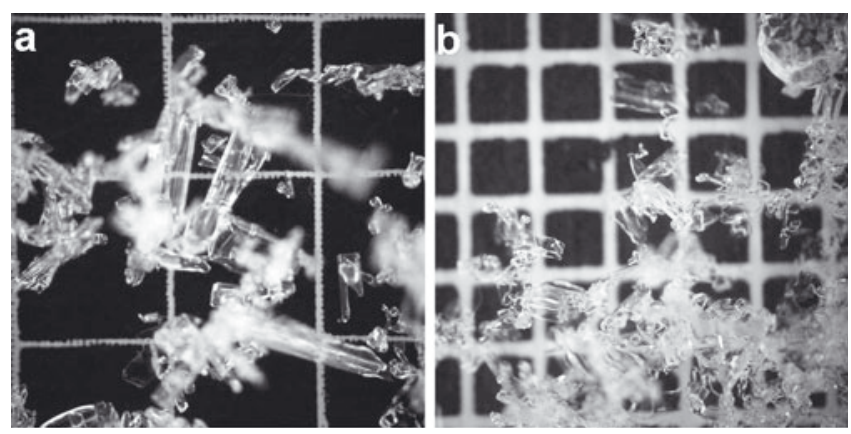

Fig. 8. Images of a near-surface facet event that occurred at the South location and persisted beneath $9 \mathrm{~cm}$ of new snow falling on the night of February 14, 2009.

primarily because only a small number of surface hoar events occurred for any one season/station. From these combined data, the mean nightly averages for each event in Table 1 ('event-only days') were compared to the nightly averages from the complete dataset ('all days').

This comparison (event-only days with all days) was accomplished using a Kolmogorov-Smirnov goodness-of-fit test (KS-test; Massey, 1951). The test provides a means to determine whether the two datasets are from the same distribution. The results of these comparisons are provided in Table 3, where the null hypothesis $\left(\mathrm{H}_{0}\right)$ was that the two datasets were from the same distribution at the 0.05 significance level. The hypothesis states that $P$-values $<0.05$ would result in a failure to reject the null hypothesis, meaning that the distributions were likely different.

The results from the $\mathrm{KS}$-test indicate that incoming longwave radiation (including the Aspirit data), snow surface temperature, wind speed, relative humidity and air/snow temperature difference likely originate from different distributions. Thus, it is assumed that these factors are related to the formation of surface hoar. Visually, each of the parameters may be compared in Figure 10, which shows empirical probability density functions (PDFs) of the complete (all) and event-only datasets. The PDFs were computed using the kernel-density estimation method with an Epanechnikov kernel (Scott, 1992; Martinez and Martinez, 2008).

The event-only data deemed significant via the KS-test were used to assign a range of conditions for surface hoar development, which are presented in the form of

Table 3. Kolmogorov-Smirnov test results for each weather variable measured, comparing the complete dataset (all days) with the event-only days

\begin{tabular}{lcc}
\hline Variable & $\mathrm{H}_{0}$ result & $P$-value \\
\hline Longwave & Reject & $5.29 \times 10^{-6}$ \\
Air temperature & Fail to reject & 0.84 \\
Snow temperature & Reject & $1.14 \times 10^{-3}$ \\
Wind speed & Reject & 0.04 \\
Wind direction & Fail to reject & 0.19 \\
Relative humidity & Reject & 0.03 \\
Air/snow temperature difference & Reject & $1.30 \times 10^{-11}$ \\
Aspirit longwave & Reject & $4.54 \times 10^{-5}$ \\
& & \\
\hline
\end{tabular}
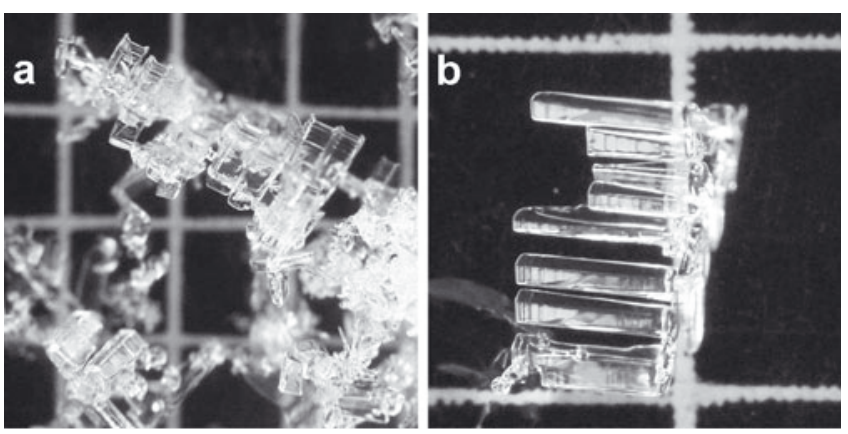

Fig. 9. Images of a near-surface facet event that occurred at the south location on 27 March 2010.

highest-density regions (HDRs) (Hyndman, 1996) in Table 4. The HDRs are a means of quantifying the empirical PDFs presented in Figure 10. For example, referring to Table 4, the upper and lower 95\% HDR values of longwave radiation are 159 and $306 \mathrm{~W} \mathrm{~m}^{-2}$, respectively. This range defines the limits such that $95 \%$ of the data from this distribution lie between these two values. Graphically, for the purpose of illustrating the definition of HDRs, the 95\% HDR is displayed for the longwave PDF in Figure 11. (For comparison, $95 \%, 68 \%$ and $38 \%$ HDRs are equivalent to 2,1 and 0.5 standard deviations about the mean of a normal distribution, respectively.)

Cooperstein and others (2004) detailed two surface hoar events that occurred at the same locations, where minimum snow surface temperatures were reported as -15.1 and $-14.2^{\circ} \mathrm{C}$ for the north site and -11.1 and $-12.5^{\circ} \mathrm{C}$ at the south site. Mean values for the night were not reported, but the minimum values for many of the events reported here were representative of the mean (i.e. the snow surface temperature remained relatively constant through the night), as shown in Figure 4 . The values from the north fell within the $25 \% \mathrm{HDR}$, and the south temperatures lie within the $75 \%$ HDR. These results indicate, if only snow surface temperatures are considered, that surface hoar formation is less probable at the south site than at the north. Cooperstein and others (2004) concluded that the surface hoar at the south location was less developed than at the north station, which indicated that the conditions were less favorable for development. Based on the current understanding, ascertaining surface hoar formation from a single parameter is problematic, but this example demonstrates how the data may begin to be applied.

A similar analysis to the above may be performed using two multi-day surface hoar events recorded in Japan (Hachikubo and Akitaya, 1997b). The average snow surface temperatures for the five nights reported were one of three temperatures: $-12,-14$ or $-16^{\circ} \mathrm{C}$. Referring to Table 4 , the $-12^{\circ} \mathrm{C}$ value is within the $75 \%$ HDR and the -14 and $-16^{\circ} \mathrm{C}$ values are within the $50 \%$ HDR.

Previously published data were generally within the $50 \%$ HDRs. Mason and others (1963) and Lang and others (1984) explain that surface hoar formed between -12 and $-16^{\circ} \mathrm{C}$. Breyfogle (1987) found formation occurred with a relative humidity of $70 \%$. Hachikubo and Akitaya (1997a) state that wind speed above the snow was $1-2 \mathrm{~m} \mathrm{~s}^{-1}$ during surface hoar formation. $\Delta T$ is reported to range from 5 to $10^{\circ} \mathrm{C}$ (Linkletter and Warburton, 1976; Feick and others, 2007). 

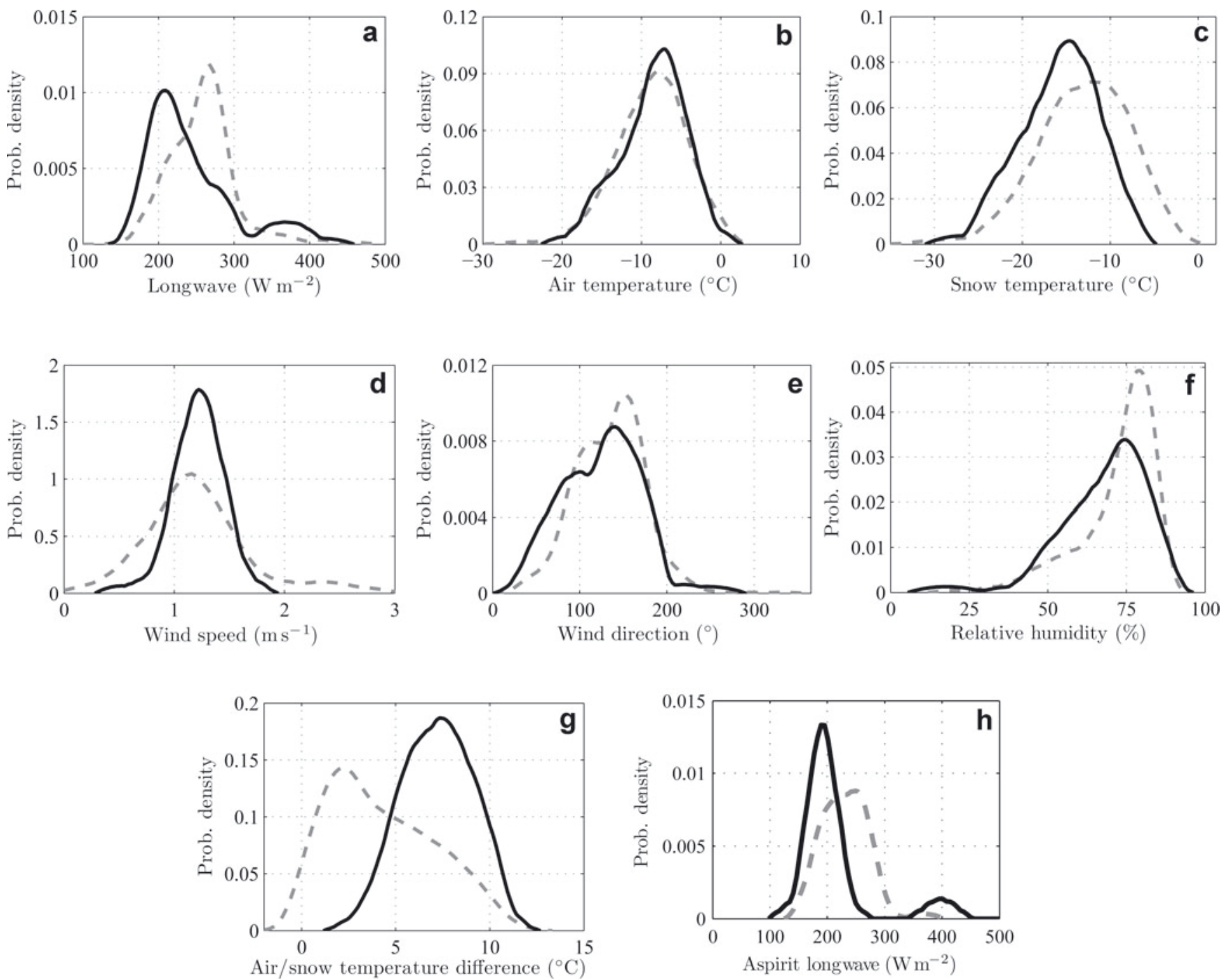

Fig. 10. PDFss comparing all recorded night-time mean weather conditions at both stations (dashed curve) to the days associated with observed surface hoar events (solid curve).

The analysis presented here is only a first step, since the ranges defined are independent. For example, considering the variance of all other parameters, surface hoar was most likely to occur with incoming longwave radiation of $178-254 \mathrm{~W} \mathrm{~m}^{-2}$ or a wind speed of $1-1.4 \mathrm{~m} \mathrm{~s}^{-1}$, etc. The word ' $\mathrm{or}^{\prime}$ is important since the interactions between the various parameters are not accounted for in this analysis. Consider an average incoming longwave radiation value of $202 \mathrm{~W} \mathrm{~m}^{-2}$ (lower 25\% HDR); for this value of longwave radiation the ideal snow temperature with respect to surface hoar formation is not necessarily (although it may be) the corresponding 25\% HDR value of $-15.7^{\circ} \mathrm{C}$. The ranges presented here are independent from each other and are presented as the first step to utilizing the YC data. Statistically analyzing the importance of the interactions is not trivial and should be the topic of future research; it is addressed numerically by Slaughter (2010).

Table 4. Limits of highest-density regions (HDRs) of environmental variables coupled to the formation of surface hoar

\begin{tabular}{|c|c|c|c|c|c|c|c|c|}
\hline \multirow[b]{2}{*}{ Variable } & \multicolumn{4}{|c|}{ Lower } & \multicolumn{4}{|c|}{ Upper } \\
\hline & $95 \%$ & $75 \%$ & $50 \%$ & $25 \%$ & $25 \%$ & $50 \%$ & $75 \%$ & $95 \%$ \\
\hline$L W\left(\mathrm{~W} \mathrm{~m}^{-2}\right)$ & 159 & 175 & 190 & 202 & 218 & 227 & 267 & 306 \\
\hline$T_{\mathrm{s}}\left({ }^{\circ} \mathrm{C}\right)$ & -22.6 & -20.8 & -17.2 & -15.7 & -13.8 & -12.3 & -10.2 & -8.98 \\
\hline$V_{w}\left(\mathrm{~m} \mathrm{~s}^{-1}\right)$ & 0.81 & 1.02 & 1.1 & 1.16 & 1.31 & 1.35 & 1.44 & 1.63 \\
\hline$R H(\%)$ & 49.1 & 58.6 & 66.9 & 70.7 & 77.9 & 80.9 & 83.6 & 87.9 \\
\hline$\Delta T\left({ }^{\circ} \mathrm{C}\right)$ & 4.22 & 5.29 & 5.92 & 6.59 & 8.07 & 8.64 & 9.16 & 10.4 \\
\hline$L W^{\mathrm{a}}\left(\mathrm{W} \mathrm{m}^{-2}\right)$ & 133 & 162 & 175 & 181 & 201 & 208 & 220 & 246 \\
\hline
\end{tabular}




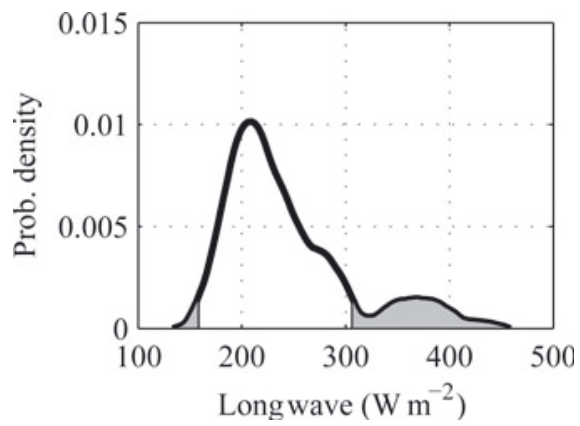

Fig. 11. Example illustrating the definition of the $95 \%$ HDR; $5 \%$ of the PDF for longwave radiation (see Fig. 10a) lies within the shaded region.

\subsection{Near-surface facets}

In similar fashion to section 4.1, the daytime mean averages of all recorded days are compared to the event-specific days. The results of these comparisons are given in Table 5 and indicate that six parameters may be statistically linked (rejection of $\mathrm{H}_{0}$ ) to the formation of near-surface facets, particularly due to radiation recrystallization. Figure 12 shows empirical PDFs demonstrating the differences between the entire dataset and the event-only days for these six terms.

Using HDRs, as in section 4.1, the empirical PDFs of Figure 12 were tabulated into ranges for the daytime mean values of each variable. Table 6 shows the ranges that were statistically linked to the near-surface facet events observed.

Morstad and others (2007) successfully formed radiationrecrystallized near-surface facets in ten laboratory experiments. The mean shortwave radiation for these experiments was one of three values: 595,755 or $1180 \mathrm{~W} \mathrm{~m}^{-2}$. Longwave radiation ranged from 270 to $320 \mathrm{~W} \mathrm{~m}^{-2}$ and relative
Table 5. Kolmogorov-Smirnov test results comparing the daytime means from all recorded data with those with near-surface facet events; the null hypothesis $\left(\mathrm{H}_{0}\right)$ was that the data were from the same distribution

\begin{tabular}{lcc}
\hline Variable & $\mathrm{H}_{0}$ result & $P$-value \\
\hline$S W$ & Reject & $9.26 \times 10^{-10}$ \\
$L W$ & Fail to reject & 0.69 \\
$S W: L W$ & Reject & $5.49 \times 10^{-9}$ \\
$S W^{\mathrm{a}}$ & Reject & $1.27 \times 10^{-7}$ \\
$L W^{\mathrm{a}}$ & Reject & $1.20 \times 10^{-10}$ \\
$S W^{\mathrm{a}}: L W^{\mathrm{a}}$ & Reject & $3.71 \times 10^{-10}$ \\
$T_{\mathrm{a}}$ & Fail to reject & 0.29 \\
$T_{\mathrm{s}}$ & Fail to reject & 0.47 \\
$V_{\mathrm{w}}$ & Fail to reject & 0.23 \\
$D i r$ & Fail to reject & 0.94 \\
$R H$ & Reject & $3.61 \times 10^{-7}$ \\
& & \\
\hline
\end{tabular}

humidity ranged between $15 \%$ and $40 \%$. A comparison of the shortwave values with the data in Table 6 indicates that only the experiments conducted with shortwave at 595 or $755 \mathrm{~W} \mathrm{~m}^{-2}$ were within the range of mean values observed in the field at the south location. The reported relative humidity values were near the limits of the 95\% HDR. This mismatch is likely the result of the laboratory experiments being performed under conditions not attainable at the south location, but may indicate an inherent flaw in the analysis.

A computation of the ratio of short- to longwave radiation using the Morstad and others (2007) laboratory experiments yielded four values: 2.2, 2.4, 2.7 and 3.9. These values, with the exception of 3.9, fit within the $75 \%$ HDR. In another study, observations made at the south station by Cooperstein and others (2004) found near-surface facet growth during
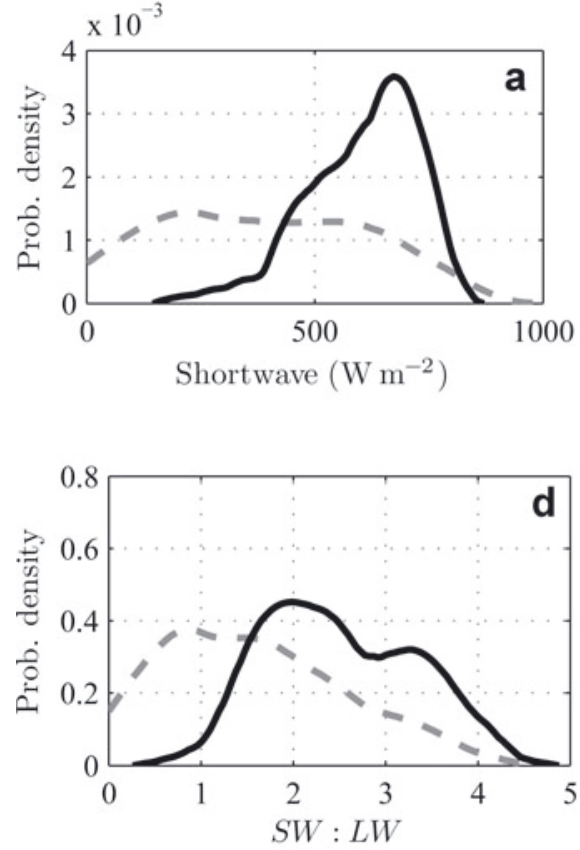
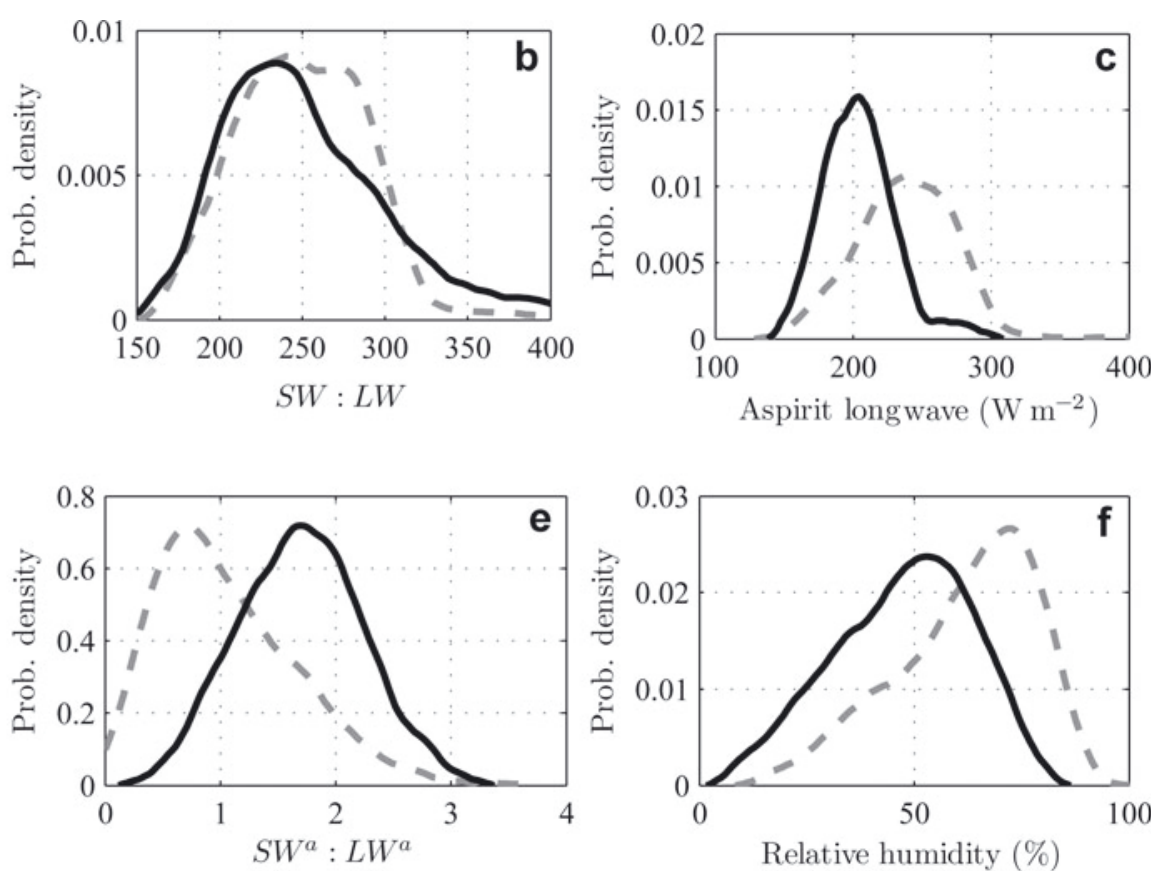

Fig. 12. PDFs comparing all recorded daytime mean weather conditions at the south site (dashed curve) to the days associated with observed near-surface facet events (solid curve). 
Table 6. Limits of highest density regions (HDRs) of environmental variables coupled to the formation of near-surface facets

\begin{tabular}{lcccccccc}
\hline & \multicolumn{3}{c}{ Lower } & \multicolumn{5}{c}{ Upper } \\
Variable & $95 \%$ & $75 \%$ & $50 \%$ & $25 \%$ & $25 \%$ & $50 \%$ & $75 \%$ & $95 \%$ \\
\hline$S W$ & 410 & 506 & 608 & 648 & 689 & 727 & 740 & 784 \\
$S W: L W$ & 172 & 193 & 205 & 221 & 244 & 259 & 282 & 330 \\
$L W^{\text {a }}$ & 161 & 177 & 185 & 195 & 210 & 217 & 225 & 243 \\
$S W^{\mathrm{a}}: L W^{\text {a }}$ & 0.753 & 1.13 & 1.42 & 1.57 & 1.89 & 2.03 & 2.25 & 2.6 \\
$R H$ & 21 & 34 & 43.1 & 48.1 & 58.2 & 61.7 & 65.7 & 71.9
\end{tabular}

$587 \mathrm{~W} \mathrm{~m}^{-2}$ of shortwave radiation, which also falls within the $75 \%$ HDR. These comparisons indicate that the data presented in Table 6 may be a reasonable tool for assessing the formation of near-surface facets due to radiation recrystallization. However, making definite statements is difficult, as there are few observations with quantified conditions available for comparison.

As explained above, the interactions between environmental values were generally not considered, with the ratio of short- and longwave radiation being the exception. The interaction of the various parameters is addressed in detail by Slaughter (2010). This interaction may be significant, since individually the short- and longwave values reported by Morstad and others (2007) did not seem to fit into the ranges observed in the field.

\section{DISCUSSION}

As discussed, particularly in the B-7 and B-8 events and events BB-3 and BB-4, the formation of surface hoar and near-surface facets are seemingly correlated. Out of the 47 days with recorded near-surface facet events, $20(43 \%)$ were observed during the daytime before or after the formation of surface hoar. This relationship is explored further using a similar approach to the previous section. First, two additional distributions are defined using the daytime period prior to and following the surface hoar events based on the dates given in section 3.1. These distributions are referred to as 'before' and 'after'. They were compared, using the KS-test with a 0.05 significance level, to the daytime distributions associated with near-surface facet events. The resulting $P$-values for these comparisons are given in Table 7 . The null hypothesis $\left(\mathrm{H}_{0}\right)$ is that the distributions are from the same population. To restate, Table 7 compares the distributions derived from the days with near-surface facet formation presented in section 3.2 with two additional distributions: one from the daytime before and one from the daytime after the formation of surface hoar. This comparison allows the following question to be answered statistically: Are the environmental conditions during the daytime hours surrounding surface hoar events similar to daytime hours associated with nearsurface facets?

For all the environmental variables considered, the daytime following a surface hoar event (i.e. 'After' in Table 7) is likely from the same distribution as the daytime for the near-surface facet events. For the day prior (i.e. 'Before' in Table 7) the same may be stated with two exceptions: the snow surface temperature, $T_{\mathrm{s}}$, and the relative humidity, $R H$.
Table 7. Resulting $P$-values from KS-tests performed comparing the daytime periods before and after surface hoar events to the days with near-surface facet formation

\begin{tabular}{lcccc}
\hline & \multicolumn{2}{c}{ Before } & \multicolumn{2}{c}{ After } \\
Variable & $P$-value & $\mathrm{H}_{0}$ result & $P$-value & $\mathrm{H}_{0}$ result \\
\hline$S W$ & 0.363 & Fail to reject & 0.283 & Fail to reject \\
$L W$ & 0.349 & Fail to reject & 0.580 & Fail to reject \\
$T_{\mathrm{a}}$ & 0.765 & Fail to reject & 0.604 & Fail to reject \\
$T_{\mathrm{s}}$ & 0.036 & Reject & 0.992 & Fail to reject \\
$V_{\mathrm{w}}$ & 0.903 & Fail to reject & 0.089 & Fail to reject \\
Dir & 0.442 & Fail to reject & 0.060 & Fail to reject \\
$R H$ & 0.000 & Reject & 0.441 & Fail to reject \\
& & &
\end{tabular}

These results indicate, with respect to the south location studied here, that the environmental conditions during the daytime periods before and after surface hoar events are similar to the conditions necessary for near-surface facet formation. This apparent relationship may be due to errors in crystal classification, but on many occasions when nearsurface facets were observed the growth was observed between a morning and afternoon observation. Thus, the relationship of the conditions between these two forms of snow crystals is likely meaningful.

\section{CONCLUSION}

Throughout three seasons, 35 surface hoar events were observed at north- and/or south-facing locations. These events were well documented, with weather data and daily observations. Five terms (incoming longwave radiation, snow surface temperature, wind velocity, relative humidity and the air/snow surface temperature difference) were shown to be associated with the formation of surface hoar. Similarly, 47 days with near-surface facet formation were observed, and indicated that three parameters may be linked to the formation of near-surface facets: incident short- and longwave radiation and relative humidity. In a comparison with the daytime environmental conditions surrounding surface hoar formation, these conditions were statistically similar to the conditions of the near-surface facet events. The data presented indicate that the conditions surrounding the formation of near-surface facets and surface hoar are linked, a result that to the authors' knowledge has not before been shown statistically.

The ranges of conditions presented in this paper for both surface hoar and near-surface facets are presented as a postulate for defining the conditions necessary for growth based on weather data. However, the data here were developed from only two locations on the same mountain and only for three seasons, so increasing the dataset would likely provide a more reliable tool. Additionally, the importance of the interactions between the parameters should be the focus of future analysis before solid conclusions may be defined. Nonetheless, the work presented in this paper is the first step. It is the most extensive field investigation of surface hoar and nearsurface facets conducted to date, adding to the existing body of knowledge regarding these crystals, and may assist in developing a tool to determine whether formation is 
based purely on environmental conditions. The cooperative relationship between Montana State University and the Yellowstone Club is planned to continue; thus this dataset as well as the various applications will continue to grow.

\section{ACKNOWLEDGEMENTS}

We thank the Yellowstone Club for providing access and resources, and the reviewers of the manuscript for helping improve the paper. A portion of the work was conducted at the Montana State University Subzero Science and Engineering Facility, which was developed with the support of US National Science Foundation (NSF) grant No. ANT-0521360 and the M.J. Murdock Charitable Trust. A portion of this work was funded by NSF grant No. EAR0635977, the NSF Graduate Teaching Fellows in K-12 Education Program and research grants from the 2000 International Snow Science Workshop and the American Avalanche Association.

\section{REFERENCES}

Adams, E.E. and 11 others. 2009. Modeling variation of surface hoar and radiation recrystallization across a slope. In Schweizer, J. and A. van Herwijnen, eds. Proceedings of the International Snow Science Workshop, 27 September-2 October 2009, Davos, Switzerland. Birmensdorf, Swiss Federal Institute for Forest, Snow and Landscape Research WSL, 97-101.

Akitaya, E. and H. Shimizu. 1987. Observations of weak layers in a snow cover. Low Temp. Sci., Ser. A46, 67-75. [In Japanese with English summary.]

Albrecht, B. and S.K. Cox. 1977. Procedures for improving pyrgeometer performance. J. Appl. Meteorol., 16(2), 188-197.

Armstrong, R.L. 1985. Metamorphism in a subfreezing, seasonal snow cover: the role of thermal and vapor pressure conditions. (PhD thesis, University of Colorado.)

Birkeland, K.W. 1998. Terminology and predominant processes associated with the formation of weak layers of near-surface faceted crystals in the mountain snowpack. Arct. Alp. Res., 30(2), 193-199.

Birkeland, K., R. Johnson and S. Schmidt. 1997. Near surface faceted crystals: conditions necessary for growth and contribution to avalanche formation, southwest Montana, USA. In Proceedings of the International Snow Science Workshop, 6-10 October 1996, Banff, Alberta. Revelstoke, B.C., Canadian Avalanche Association, 75-80.

Birkeland, K.W., R.F. Johnson and D.S. Schmidt. 1998. Nearsurface faceted crystals formed by diurnal recrystallization: a case study of weak layer formation in the mountain snowpack and its contribution to snow avalanches. Arct. Alp. Res., 30(2), 200-204.

Breyfogle, S.R. 1987. Growth characteristics of hoarfrost with respect to avalanche occurrence. In Proceedings of the International Snow Science Workshop, 22-25 October 1986, Lake Tahoe, California. Homewood, CA, ISSW Workshop Committee, 216-222.

Campbell Scientific. 2007. Eppley PIR Precision Infrared Radiometer. (Logan, UT, Campbell Scientific Inc.) Appl. Note 2RA-H.

Colbeck, S.C. 1988. On the micrometeorology of surface hoar growth on snow in mountainous area. Bound.-Layer Meteorol., 44(1-2), 1-12.

Colbeck, S.C. 1989. Snow-crystal growth with varying surface temperatures and radiation penetration. J. Glaciol., 35(119), $23-29$.
Cooperstein, M., K.W. Birkeland and K. Hansen. 2004. The effects of slope aspect on the formation of surface hoar and diurnally recrystallized near-surface faceted crystals: implications for avalanche forecasting. In Elder, K., Proceedings of the International Snow Science Workshop, 19-24 September, 2004, Jackson Hole, Wyoming, USA. Jackson hole, WY, International Snow Science Workshop, 83-93.

Feick, S., K. Kronholm and J. Schweizer. 2007. Field observations on spatial variability of surface hoar at the basin scale. J. Geophys. Res.,112 (F2), F02002. (10.1029/2006JF000587.)

Fierz, C. 1998. Field observation and modelling of weak-layer evolution. Ann. Glaciol., 26, 7-13.

Fukuzawa, T. and E. Akitaya. 1993. Depth-hoar crystal growth in the surface layer under high temperature gradient. Ann. Glaciol., 18,39-45.

Gow, A.J. 1965. On the accumulation and seasonal stratification of snow at the South Pole. J. Glaciol., 5(40), 467-477.

Hachikubo, A. and E. Akitaya. 1997a. Effect of wind on surface hoar growth on snow. J. Geophys. Res., 102(D4), 4367-4373.

Hachikubo, A. and E. Akitaya. 1997b. Surface hoar growing for several days. In Proceedings of International Snow Science Workshop, 6-10 October 1996, Banff, Alberta. Revelstoke, BC, Canadian Avalanche Association, 86-89.

Hyndman, R.J. 1996. Computing and graphing highest density regions. Am. Stat., 50(2), 120-126.

LaChapelle, E.R. 1970. Principles of avalanche forecasting. In Gold, L.W. and G.P. Williams, eds. Ice engineering and avalanche forecasting and control. Proceedings of conference held 23-24 October 1969, Calgary, Alberta. Ottawa, National Research Council of Canada. Associate Committee on Geotechnical Research, 106-112.

LaChapelle, E.R. and R.L. Armstrong. 1977. Temperature patterns in an Alpine snow cover and their influence on snow metamorphism. Boulder, CO, University of Colorado. Institute of Arctic and Alpine Research. (Technical Report.)

Lang, R.M., B.R. Leo and R.L. Brown. 1984. Observations on the growth process and strength characteristics of surface hoar. In Proceedings of the International Snow Science Workshop, 2427 October 1984, Aspen, Colorado. Aspen, CO, ISSW Workshop Committee, 188-195.

Linkletter, G.O. and J.A. Warburton. 1976. A note on the contribution of rime and surface hoar to the accumulation on the Ross Ice Shelf, Antarctica. J. Glaciol., 17(76), 351-354.

Martinez, W.L. and A.R. Martinez. 2008. Computational statistics handbook with MATLAB. Second edition. Boca Raton, FL, Chapman and Hall/CRC Press.

Mason, B.J., G.W. Bryant and A.P. van den Heuvel. 1963. The growth habits and surface structure of ice crystals. Philos. Mag., 8(87), 505-526.

Massey, F.R., Jr. 1951. The Kolmogorov-Smirnov test for goodness of fit. J. Am. Stat. Assoc., 46(253), 68-78.

Morstad, B.W., E.E. Adams and L.R. McKittrick. 2007. Experimental and analytical study of radiation-recrystallized near-surface facets in snow. Cold Reg. Sci. Technol., 47(1-2), 90-101.

Nakaya, U. 1954. Snow crystals: natural and artificial. Cambridge, MA, Harvard University Press.

Schweizer, J. and M. Lütschg. 2001. Characteristics of humantriggered avalanches. Cold Reg. Sci. Technol., 33(2-3), 147-162.

Scott, D.W. 1992. Multivariate density estimation: theory, practice, and visualization. New York, etc., Wiley.

Seligman, G. 1936. Snow structure and ski fields. London, Macmillan \& Co.

Slaughter, A. 2010. Numerical analysis of conditions necessary for near-surface snow metamorphism. (PhD thesis, Montana State University.)

Slaughter, A.E. and E.E. Adams. 2009. Numerical investigation of factors causing near-surface metamorphism. In Schweizer, J. and A. van Herwijnen, eds. Proceedings of the International Snow Science Workshop, 27 September-2 October 2009, Davos, 
Switzerland. Birmensdorf, Swiss Federal Institute for Forest, Snow and Landscape Research WS, 72-76.

Slaughter, A.E. and E. Adams. In press. Field and analytical examination of near-surface facets. In Proceedings of the International Snow Science Workshop, 17-22 October 2010, Lake Tahoe, California. Squaw Valley, CA, International Snow Science Workshop.

Slaughter, A.E. and 8 others. 2009. An investigation of radiationrecrystallization coupling laboratory and field studies. Cold Reg. Sci. Technol., 59(2-3), 126-132.
Staples, J.M., E.E. Adams, A.E. Slaughter and L.R. McKittrick. 2006 Slope scale modeling of snow surface temperature in topographically complex terrain. In Gleeson, J.A., ed. Proceedings of the International Snow Science Workshop, 1-6 October, 2006, Telluride, Colorado. Telluride, CO, International Snow Science Workshop, 806-814.

Stössel, F., M. Guala, C. Fierz, C. Manes and M. Lehning. 2010. Micrometeorological and morphological observations of surface hoar dynamics on a mountain snow cover. Water Resour. Res., 46(W4), W04511. (1029/2009WR008198.)

MS received 11 June 2010 and accepted in revised form 3 February 2011 